International

Medical Society

http://imedicalsociety.org

\title{
Quality of Life in Caregivers of Children and Adolescents with Mental Disorders
}

ORIGINAL

\begin{abstract}
Manuela Carla de Souza Lima Daltro ${ }^{1}$, Elicarlos Marques Nunes², José Cássio de Moraes ${ }^{3}$, Patrícia Martins Montanari ${ }^{4}$, Juliane de Oliveira Costa Nobre ${ }^{5}$, Ana Carolina Miranda Luna Marques, ${ }^{6}$ Vandezita Dantas de Medeiros Mazzaro7,

Nicoly Negreiros de Siqueira Mariano7, Regina Maria Giffoni Marsiglia ${ }^{8}$
\end{abstract}

\section{Abstract}

Introduction: Psychiatric disorders in childhood and adolescence are extremely prevalent, affecting approximately 1 in 10 Brazilian children. Child mental health affects all areas of development and impacts the physical and mental health of the family and in school performance, with its obvious consequences in adulthood.

Objective: The objective was to evaluate the perception of quality of life of children and adolescents with mental disorders caregiver's.

Methodology: There were participating 64 caregivers of children and adolescents with mental disorders who attend one capside at a city of Paraiba backlands. Data from samples were obtained through a socio demographic questionnaire and the quality of life questionnaire WHOQOL Bref. Data were analyzed using the statistical program Statistical Package for Social Sciences (SPSS).

Results: The results showed that sixty (93.8\%) caregivers were women, 27 (42.2\%) completed high school, 40 (62.5\%) were housewives, 31 (48.4\%) were married, 46 (71.9\%) were Catholic, 55 (85.9\%) were mothers of children and adolescents and the overall score for quality of life WHOQOLBref ranged from 12.5 to 62.5 (mean = 43.9; $\mathrm{SD}=12.0)$ and that the lowest average was found in the psychological domain $(m=40.1)$.
1 Physical Therapist. Master in Health Sciences. Teacher Department of Physical Therapy of Patos Integrated College (PB), Brazil.

2 Nurse. Master in Public Health. Teacher Department of Nursing of Patos Integrated College, Patos (PB), Brazil.

3 Doctor. Department of Social Medicine. Medical Sciences College. São Paulo Holy House. São Paulo, SP, Brazil.

4 Master and PDH in Public Health from the University of São Paulo.

5 Nurse. Master in health sciences. Teacher of Nursing and Public Health. Department of Nursing of Patos Integrated College, Patos (PB), Brazil.

6 Physiotherapist. Master's Degree in Health Sciences. Teacher Department of Physical Therapy, Santa Maria School, Cajazeiras - PB, Brazil.

7 Doctors. Master's in Health Sciences. Teacher Department of Medicine of the Patos Integrated College, Patos (PB), Brazil.

8 Social Scientist. PhD in Political Sciences. Medical Sciences at São Paulo Holy House College. São Paulo, SP, Brazil.

\section{Contact information:}

\section{Elicarlos Marques Nunes.}

Address: Rua Bossuet Wanderley, Bairro: Centro, 521 Apt 101.

Cep: 58700-410. Patos, PB.

झ elicarlosnunes@yahoo.com.br 
Conclusion: At the end of it, the results of this study may influence on the availability of social support networks, on the creation of socio-sanitary laws, on the structure and adequacy of mental health services, since the health of children and adolescents depends on the caregiver health.

\author{
Keywords \\ Adolescent; Caregiver; Child; \\ Quality of life; \\ Mental disorder.
}

\section{Introduction}

Psychiatric disorders in childhood and adolescence are extremely prevalent, affecting approximately 1 in 10 Brazilian children [1-2]. In addition, it is also the leading cause of health disability related in this age group with lasting effects throughout life.

Child mental health affects all areas of development and impacts the physical and mental health of the family and in school performance, with its obvious consequences in adulthood. The impacts of family distress are difficult to measure, conflict and inadequate social performance in childhood, but retrospective studies indicate these events as early markers of mental disorders in adults [3-4].

Meet the basic needs of psychiatric patients has become part of the family routine that includes coordinate their daily activities, manage their medication, accompany them to health services, deal with their problem behavior and episodes of crisis, provide them with social support, bear costs and overcome difficulties these tasks. Becoming a caregiver of a psychiatric patient can generate overload, because it is a drop in expected life cycle, which assumes that adults are independent [5].

Studies have shown that the intensity of the burden on families has been related with some variables, such as: patient characteristics (diagnosis, severity of symptoms, degree of dependence, age, gender, disease duration and number of hospitalizations), kinship and contact frequency between caregiver and patient, and caregiver characteristics (gender, age, education and socioeconomic status [6-7].
The World Health Organization (WHO) defines the concept of quality of life basing it on three assumptions: subjectivity, multidimensionality and the presence of both positive and negative dimensions. Thus, it defines quality of life as "the individual's perception of its position in life, in the context of culture and value systems in which he lives and in relation to his goals, expectations, standards and concerns [8]".

In Brazil the theme quality of life now has meaning and importance in health care research over the last decade, from 1992, when the average number of publications has increased seven times compared to the previous ten years [9].

Understand how people live, their physical and emotional needs as well as what aspects of their life affect their wellbeing, it is essential for the improvement of rehabilitation programs and treatment modalities in the design of these authors [10].

International studies have investigated the experience of family members who care for psychiatric patients since the 1950s and has intensified from the 1970s. When reviewing research in this area, they found that family caregivers of psychiatric patients feel overwhelmed [11-12]. Other international studies have also pointed to the presence of overhead in family caregivers despite the satisfaction that also presented for taking care of these people [13].

Brazilian studies on this topic are still scarce. Identified only 21 national studies that have addressed, directly or indirectly, issues related to families of psychiatric patients [14]. These studies are generally 
qualitative and investigated the families' perception of their coexistence with patients, not specifically addressing the evaluation of the burden on caregivers. As regards the caregivers of children and adolescents with mental disorders, it assessed the quality of life in caregivers of children and adolescents with Autism, confirming it has a negative impact on quality of life of caregivers [15].

Knowing then the prevalence of mental disorders in the group of children and adolescents and the lack of Brazilian studies and especially in northeastern Brazil, came the next problem: the perception of quality of life of caregivers of children and adolescents with mental disorders? Thus, this study aimed to: assess the quality of life of caregivers of children and adolescents with mental disorders attended at a Psychosocial Care Center in Paraiba.

\section{Methodology}

A cross-sectional study was conducted. Data collection was performed at a Psychosocial Care Center for Children and Adolescents (CAPSi in the town of Patos, Paraíba, in the first semester of 2015 after approval by the Ethics Committee in research of Patos Integrated College and Approval of the Ethics Committee of Medical Sciences in College of São Paulo Holy House).

It was included in the study all caregivers of children and adolescents with mental disorders treated at CAPSi with availability for scheduling an interview for data collection during the period from 01/05 to 06/30/2015 and it was directly responsible (dispense over $50 \%$ of their time) for the care of the child or adolescent with mental disorders who present clinical diagnosis issued by a doctor and that are followed at CAPSi.

For data collection were used: sociodemographic questionnaire and the questionnaire of quality of life WHOQOL-Bref. The demographic questionnaire aimed to obtain information on the demographic and socioeconomic profile of caregivers, and involved issues such as: age, education, occupation, marital status, religion, kinship with the child / adolescent, moreover, it was collected data about the child/adolescent: sex, age, diagnosis.

The WHOQOL-Bref is a specific instrument for the measurement of quality of life, created by the WHO Quality of Life Group from WHOQOL 100. It is a shortened version of WHOQOL 100. The WHOQOLBref contains 26 questions, two general questions and the other 24 represent each of the 24 facets that make up the originall instrument [8].

It was calculated the WHOQOLBref scores using the statistical program Statistical Package for Social Sciences (SPSS 22.0), according to the proposal of WHO [8].

The description of quantitative variables was performed by calculating measures of central tendency (mean) and dispersion (standard deviation); for qualitative variables were calculated absolute frequencies ( $n$ ) and relative (\%). For the quantitative variables the verification was carried out of the normality of the data by the Kolmogorov-Smirnov which allowed the choice of non-parametric tests (Mann-Whitney test).

It was recognized statistical significance level of $5 \%$.

In assessing sociodemographic characteristics with the scores of WHOQOL Bref, seeking greater uniformity was required reagrup the ages of 24-39 years and 40-65 years; schooling in 2 groups: illiterate with elementary school (incomplete or complete) and high school to higher education; marital situation: caregivers who have partners and those without partners, occupations: in housewives and those who work outside the home, retirees were excluded because there were only 4 caregivers and it could not be grouped into any other category; and the per capita monthly income of up to $1 / 2$ minimum wage per capita and above $1 / 2$ minimum wage.

This research followed the norms of Resolution $466 / 12$ of the National Health Council and was referred to the Ethics Committee for Research Involving 
Human Subjects of Patos Integrated College, and was approved by the opinion number 829.843 of 09/10/2014.

\section{Results}

\section{Characterization of caregivers}

It were included in the study 64 caregivers of children and adolescents with mental disorders who had consecutively willingness to participate in the study during the period of data collection. There were no refusals. The age of the caregivers varied from 24 to 65 years (mean $=38.9$ years, $S D=8.6$ years). Sixty (93.8\%) caregivers were women, 27 (42.2\%) completed high school, 40 (62.5\%) were housewives, 31 (48.4\%) were married, 46 (71.9 \%) were Catholic, 55 (85.9\%) were mothers of the children and adolescents.

\section{Characterization of children/adolescents}

Forty-five (70.3\%) CAPSi users were male. The age of the children and adolescents ranged from three to 17 years $($ mean $=10.6$ years, $S D=3.7$ years). Twenty-eight (43.8\%) children were aged between six and 10 years. The most frequent diagnosis was mental retardation ( $n=41,64.1 \%$ )

(Table 2).

The overall score for quality of life WHOQOLBref ranged from 12.5 to 62.5 (mean $=43.9, \mathrm{SD}=12.0$ ). The WHOQOLBref domain with the lowest average score was the psychological (Table 1).

In assessing the socioeconomic profile with the perception of quality of life of these caregivers, were related the variables age group, education, marital status, occupation and per capita monthly income to the fields of WHOQOLBref. According to the tables 2, 3, 4, 5 .

The table 3, described above, shows that the level of education statistically interfere in the physical and environmental domains, as in the general index of quality of life.

When correlated with marital status and domain
Table 1. Quality of life, assessed by WHOQOL-Bref, of caregivers of children and adolescents with mental disorders, seen at CAPSi, in the city of Patos-PB, 2015 ( $n=64)$.

\begin{tabular}{|l|c|c|c|c|}
\hline \multicolumn{1}{|c|}{ DOMAINS } & Average & $\begin{array}{c}\text { Standard } \\
\text { deviation }\end{array}$ & Minimum & Maximum \\
\hline $\begin{array}{l}\text { IGQV* } \\
\text { (0-100) }\end{array}$ & 43.9 & 12 & 12.5 & 62.5 \\
\hline $\begin{array}{l}\text { Physical } \\
\text { (0-100) }\end{array}$ & 54.3 & 8.3 & 32.1 & 75 \\
\hline $\begin{array}{l}\text { Psychological } \\
\text { (0-100) }\end{array}$ & 40.1 & 8.8 & 16.7 & 54.2 \\
\hline $\begin{array}{l}\text { Personal } \\
\text { relationships }\end{array}$ & 49.2 & 11.4 & 25 & 75 \\
\hline $\begin{array}{l}\text { (0-100) } \\
\text { Environment }\end{array}$ & 51.4 & 8.6 & 34.4 & 84.4 \\
\hline (0-100) & & & * Quality of Life General Index. \\
\hline
\end{tabular}

Table 2. Descriptive statistics of WHOQOL Bref domains of caregivers of children and adolescents with mental disorders, seen at CAP$\mathrm{Si}$, the city of Patos-PB, according to age group, in 2015.

\begin{tabular}{|l|c|c|c|}
\hline \multirow{2}{*}{\multicolumn{1}{|c|}{ DOMAINS }} & \multicolumn{3}{|c|}{ Age group } \\
\cline { 2 - 4 } & $\begin{array}{c}\text { Between 24 } \\
\text { and 39 years }\end{array}$ & $\begin{array}{c}\text { Between 40 } \\
\text { to 65 }\end{array}$ & $\mathrm{P} * *$ \\
\hline IGQV & 35.07 & 29.4 & 0.2 \\
\hline Physical & 35.19 & 29.26 & 0.2 \\
\hline Psychological & 35.77 & 28.55 & 0.11 \\
\hline Personal relationships & 36.06 & 28.21 & 0.07 \\
\hline Environment & 35.2 & 29.24 & 0.19 \\
\hline
\end{tabular}

Table 3. Descriptive statistics of WHOQOL Bref domains of caregivers of children and adolescents with mental disorders, seen at CAPSi, the city of Patos-PB, in education, in 2015.

\begin{tabular}{|l|c|c|c|}
\hline \multirow{2}{*}{\multicolumn{1}{c|}{ DOMAINS }} & \multicolumn{3}{|c|}{ Education } \\
\cline { 2 - 4 } & Illiterate and & $\begin{array}{c}\text { High school } \\
\text { primary school } \\
\text { and higher } \\
\text { education }\end{array}$ & P** \\
\hline IGQV & 25.27 & 37.45 & $0.00 *$ \\
\hline Physical & 24.42 & 38.03 & $0.00 *$ \\
\hline Psychological & 29.21 & 34.75 & 0.23 \\
\hline Personal relationships & 31.75 & 33.01 & 0.77 \\
\hline Environment & 26.25 & 36.78 & $0.02 *$ \\
\hline & & ** Mann-Whitney test.
\end{tabular}


Vol. 9 No. 23 doi: $10.3823 / 1894$

scores of the WHOQOL Bref, it can be seen that no domain has a statistically significant difference by the presence of companion.

In the current study, the differences in occupation and per capita monthly income, did not cause significant changes in the perception of quality of life, as the tables below: (tables 4, 5).

Table 4. Descriptive statistics of WHOQOL Bref of caregivers of children and adolescents with mental disorders seen at CAPSi, the city of Patos-PB, according to the occupation, in 2015.

\begin{tabular}{l|c|c|c|}
\hline \multirow{2}{*}{\multicolumn{1}{|c|}{ DOMAINS }} & \multicolumn{3}{|c|}{ Education } \\
\cline { 2 - 4 } & Housewife & $\begin{array}{c}\text { Work outside } \\
\text { the home }\end{array}$ & $P^{* *}$ \\
\hline IGQV & 29.84 & 31.83 & 0.66 \\
\hline Physical & 28.56 & 24.38 & 0.21 \\
\hline Psychological & 29 & 33.5 & 0.34 \\
\hline Personal relationships & 29.16 & 33.18 & 0.37 \\
\hline Environment & 28.83 & 33.85 & 0.28 \\
\hline & & $* *$ & Mann-Whitney test. \\
\hline *** The retired group has not been evaluated in comparison because there & were only four individuals and not give to include them in another category.
\end{tabular}

Table 5. Descriptive statistics of WHOQOL Bref domains of caregivers of children and adolescents with mental disorders, seen at CAPSi, the city of Patos-PB, according to the monthly income per capita in the year 2015.

\begin{tabular}{|l|c|c|c|}
\hline \multirow{2}{*}{\multicolumn{1}{c|}{ DOMAINS }} & \multicolumn{4}{|c|}{ Monthly Income per capita } \\
\cline { 2 - 4 } & Until 1/2 MS* & Over 1/2 MS* & $p * *$ \\
\hline IGQV & 29.77 & 36.76 & 0.12 \\
\hline Physical & 30.22 & 36.06 & 0.21 \\
\hline Psychological & 30.9 & 35 & 0.38 \\
\hline Personal relationships & 32.44 & 32.6 & 0.97 \\
\hline Environment & 29.4 & 37.34 & 0.09 \\
\hline
\end{tabular}

\section{Discussions}

In the present study it can observed the frequency of female caregivers (93.8\%), agreeing to various studies, including the Souza Filho and colleagues [17], confirming that in the mental health services is constant the presence of female caregivers because the care relationships were historically built over time, being observed gender roles in them.

As regards the age of the caregivers, it was observed that the median age was of 38.92 years. Studies show that the higher the age of the caregiver, the worse the quality of life. This is due to the fact that older caregivers already have some limitations (physical and cognitive) that hinder the care of the mentally ill, because to be able to perform some acts inherent to the care it is needed to perform tasks involving physical exertion and cognitive ability [18].

There was great variety in terms of schooling, since most have completed high school. Oliveira and colleagues [19] claim that some dreams are interrupted, delayed or modified, both in professional and personal life, as a result of any fatality, in this case the birth of a child with special needs, which requires a lot of dedication. This fact can not justify the no continuity to study of the great majority of carers with a child's illness.

There is a higher incidence of marriage, but there is a high number of single and divorced. In a study of Quadros and colleagues [21] performed with CAPS caregivers of users, in which 936 people were evaluated, it was found that $59.7 \%$ of respondents live with a partner.

It can be seen that all caregivers have religion and the mothers, for the most part, become the child's caregivers. Study with family members of CAPS patients showed that all respondents had religion, and resorted to it, asking for divine help to address the difficulties encountered in patient care [22].

Vieira and colleagues [23] reported in their research that the mother is usually the primary caregiver of children with special needs, since in most 
cases the family is not psychologically and physically prepared for the situation and leaves the child with the mother: in this new life phase are generated affective conflicts between the couple because of the great responsibility they will have with the disabled child, in relation to financial costs, breakdown of society and family members, or even the father.

The average age of children and adolescents that caregivers care have is 10.6 years, with a minimum age of 3 and maximum of 17 years, SD $=3.73$. Nineteen $(29.7 \%)$ were girls and $45(70.3 \%)$ are boys. In the study the average age of CAPSi users was 11.1 years [24]. Girls are less susceptible to psychosocial stresses of childhood [25].

As regards the diagnostic profile of children, the present study shows that mental retardation it the most commonly condition found in $64.1 \%$ of cases. Yeargin-Allsopp et al [27] reported that mental retardation (MR) is the most common neuropsychiatric disorders in children and adolescents. The prevalence rate traditionally cited is $1 \%$ of the youth population, though some authors mention rates of 2 to $3 \%$, and there are estimates of up to $10 \%$.

The result of WHOQOL Bref assessment scores shows that the lowest score is found in the psychological domain with 40.1, followed by social relationships domain with 49.2, 51.4 in environment and physical domain score of 54.3. In studies showed that caregivers of people with mental disorders have a perception of low social support, especially in the field of "satisfaction with social activities" and "satisfaction with the family [28]."

Comparison of means with other studies, carried out from the application of the WHOQOL-BREF, demonstrates that the quality of life of caregivers is worthy of attention. In a study of 20 mothers of children with pervasive developmental disorders showed the following results: Physical domain: 69.4; Psychological: 66.85; Social relations: 67.5; and Environment: 60.8 [29]. It can be seen that these results are superior to those obtained in our study.
Study with parents of children and adolescents with pervasive developmental disorder (PDD), mental retardation (MR) and cerebral palsy (CP) used the WHOQOL Bref for evaluation of quality of life. For comparison purposes, there were also evaluated 57 caregivers without disorder, which was called control group (CG). Optionally, here we will be only presented the results of the mothers in the WHOQOL-BREF domains: mothers of patients with PDD the results showed 53.94 in the field Physical, Psychological at 57.59, 58.97 in Social Relationships and 48.96 in Environment; in patients with MRI, mothers showed in the field Physical: 64.65 in Psychological: 68.79, in Social Relations: 69.73 and Environment: 57.14 ; mothers of children/adolescents with CP domain resulted in 60.87 in the physical domain, 67.20 in the Psychological, Social Relations in 66.97 and 54.64 on the Environment; and the mothers in the control group showed in the field Physical: 68.45 in Psychological: 64.38, in Social Relations: 72.22 and Environment: 54.24 [30].

Looking at the correlation of age with perceived quality of life, our study did not observe significant differences according to age group. But old age is associated with worse quality of life levels associated with health [31]. The role of the informal caregiver himself is tiresome and when summed some of the problems inherent to the normal aging process as depression, physiological stress, and degenerative diseases will produce a decrease in the caregiver's quality of life [32].

The differences in the variables: marital status and monthly per capita income did not affect the perception of quality of life in any domain ( $p>0.1$ ). The presence of a companion in the house and paid work are important factors that could alleviate the suffering of individuals, to the extent that these can share the emotional burden, financial costs and tasks involving the day-to-day carer [21].

In relation to income an important aspect to be noted is that when the subject quality of life is studied, the household income question it is important 
to be analyzed, because higher family income can determine better living conditions. In the present study can not be observed significant changes in quality of life due to income, it may be because the studied population falls, the vast major, in the average salary range of low income.

Education levels affected the overall index of quality of life and the physical domains and environments, noting that the highest scores are found in caregivers who have high school and college level. Individuals with higher education are able to perceive the restricting in keep their social life as a result of care provided to the patient and, consequently, present more subjective impact of the disease on their QoL [33].

Regarding the occupation, we did not find a statistically significant correlation in the differences of caregivers been homemakers or work outside, but the lowest scores are found in housewives. This can be explained that the abandonment of paid work can generate a higher rate of stress for caregivers, for having to face the double challenge of caring and providing for their families because been a caregiver of a child and / or adolescent with special needs require much dedication, and it takes comfort and appropriate resources, and for that it's necessary a stable financial income [34]. The fact that caregivers with an active professional life have more time for social activities and spend less time with the mentally ill, has a positive effect on their quality of life [35].

\section{Final considerations}

The present study aimed to evaluate Quality of Life of caregivers of children and adolescents with mental disorders and determinants variables of it, because children and adolescents are under development and their health depends on the caregiver's health, showing that being a caregiver of children or adolescents with mental disorders decreases the perception of quality of life.
Given what we have seen, I believe that the results of this study may influence in the availability of social support networks, in the creation of socio-sanitary laws, in the structure and adequacy of mental health services. That said, I consider that this is not the end of a job, but rather the beginning of a long journey in searching of improvements in quality of life of caregivers.

\section{References}

1. Fleitlich BW, Goodman R. Deployment and implementation of communitary mental health services for children and adolescents [editorial]. Rev Bras Psiquiatr. 2002; 24 (1): 2.

2. Anselmi L, Fleitlich-B Bilyk, Menezes AM, Araujo CL, Rohde LA. Prevalence of psychiatric disorders in a Brazilian birth cohort of 11-year-olds. Soc Psychiatry Psychiatr Epidemiol. 2010; 45 (1): $135-42$

3. Greenberg MT, Domitrovich C, Bumbarger B. The prevention of mental disorders in school-aged children: current state of the field. Prev Treat. 2001; 4 (1): 51-9.

4. Huang L, Stroul B, Friedman R, Mrazek P, B Friesen, Pires S, Mayberg S. Transforming mental health care for children and Their families. Am Psychol. 2005; 60 (6): 615-27.

5. Ferriolli SHT, IN Marturano, Puntel LP. Family background and problems in child mental health in the Family Health Program. Rev Public Health. 2007; 41 (2): 251-9.

6. Zarit SH. Interventions with family caregivers. In: Zarit SH, Knight BG (Eds.). A guide to psychotherapy and aging: effective clinical interventions in a life-stage context. Washington, DC, US: American PsychologicalAssociation; 1996. p.139-59.

7. Nakamura E. Anthropology. In: Assumpção Junior FB, Kuczynski E (Org.). Psychiatry Treaty of childhood and adolescence. Sao Paulo: Atheneu; 2003. p. 59-62.

8. The WHOQOL Group. Development of the World Health Organization WHOQOL-Bref Quality of Life Assessment. Psychol Med 1998; 28 (3): 551-8. Available in: http://journals.cambridge. org/action/displayAbstractfromPage $=$ online $\&$ aid $=25793 \&$ fileld $=$ S0033291798006667

9. Dantas SAN, Sawada NO Malerbo MB. Research on quality of life: review of scientific production of public universities of São Paulo. Rev Latin Am Enferm.2003; 11 (4): 532-8.

10. Almeida AC, Loureiro SR. Quality of life in post-TMO. In: Multidisciplinary and reform: issues, practices and policies. Annais VIII Cycle of Mental Health, 2000; Ribeirão Preto. [Resume]. Ribeirão Preto: San Francisco printing and editing; 2000. p. 65-6

11. Maurin JT Boyd CB. Burden of mental illness on the family: a critical review. Arch PsychiatrNurs. 1990; 4 (2): 99-107.

12. THE Loukissa. Family burden in chronic mental illness: a review of research studies. J AdvNurs. 1995; 21 (2): 248-55. 
13. Greenberg, J. S.; Kim, H.W.; Greenley, JR - Factors associated with Subjective burden in siblings of adults with severe metal illness. American Journal of Orthopsychiatry 67 (2): 231-241, 1997

14. Waidman MAP. Caring for families of people with mental disorders in the paradigm of institutionalization. Thesis (PhD). Florianopolis: Federal University of Santa Catarina; 2004.

15. Cuvero MM. Quality of life of caregivers of children and adolescents with autism. Thesis (MS). Uberlandia: Federal University of Uberlândia; 2008.

16. Fleck MPA, Louzada S, Xavier M, Chachamovich E, Vieira G, Santos L, Pinzon V. Application of the Portuguese version of the assessment tool of quality of life of the World Health Organization (WHOQOL-100). Rev Public Health, Rio de Janeiro. 1999; 33 (2): 198-205.

17. Souza Filho MD, Sousa AO, Parente ACBV, Martins MCC. Overload evaluation in family caregivers of schizophrenic adult patients. PsicolEstud. 2010; 15 (3): 639-47.

18. Silva, V. Quality of life of the elderly: Elderly care, duty of who?. Magazine academic space. N.110 July 2010.

19. Oliveira CG, Albuquerque PB. Diversity of Results in the study of attention deficit and hyperactivity disorder. Psychology: Theory and Research. 2009; 25 (1): 93-102.

20. Kantorski LP, VMR Garden, Delpino GB, Lima LM, Schwartz E, Heck RM. Profile of family caregivers of community mental health services users in southern Brazil. Rev Gaucha Enferm. 2012; 33 (1): 85-92

21. Quadros LCM, Gigante DP, LP Kantorski, Jardim VMR. Minor psychiatric disorders in family caregivers of community mental health services users in southern Brazil. Cad Public Health. 2012; 28 (1): 95-103

22. Cavalheri SC. Transformation of the care model in mental health and its impact on the family. RevBrasEnferm. 2010; 63 (1): 51-7.

23. Vieira NGB, Mendes NC, Frota LMCP, Frota MA. The daily life of mothers of children with cerebral palsy. RBPs. 2008; 21 (1): 55-60.

24. Hoffmann MCCL, Santos DN, Mota ELA. Characterization of users and services provided by community mental health services for Children and Adolescents. Cad Public Health, Rio de Janeiro. 2008; 24 (3): 633-42

25. Telles, L. E. B. (2006). Alcohol, drugs and crime. Journal of Psychiatry, 28, 69-73.

26. Delfini PSS, Barbosa CD, Fonseca FL, Tavares CM, Reis AOA. Users of the profile of a center for children's psychosocial care of greater São Paulo, Brazil. Rev Bras Growth Development Hum 2009; 19 (2): 226-36.

27. Yeargin-Allsopp M, Murphy CC, Cordero JF, Decouflé $P$, Hollowell JG. Reported biomedical causes and associated medical conditions for mental retardation Among 10-year-old children, metropolitan Atlanta 1985 to 1987. Dev Med Child Neurol. 1997; 39 (3): 142-9.
28. Sequeira CAC. Adaptation and validation of Caregiver Overload Scale Zarit. Rev Enferm Referência. 2010; 12: 9-16. [online] Available at: http://web.b.ebscohost.com/abstract?direct=true\& profile $=$ ehost $\&$ scope $=$ site $\&$ authtype $=$ crawler\&jrn $=08740283 \&$ $\mathrm{AN}=54284772 \& \mathrm{~h}=0 t 7 \mathrm{IOVyUa \%} 2 \mathrm{bktGYU3vHK3aFtaue8PsuJZu}$ \%2bJTdMegxGaPY4VHKmCxFEd9cl\%2fN9cA\%2b6DU26s2gx XyO0509SGalKg\%3d\%3d\&crl=c\&resultNs=AdminWebAuth\&r esultLocal=ErrCrINotAuth\&crlhashurl=login.aspx\%3fdirect\%3d true $\% 26$ profile $\% 3$ dehost $\% 26$ scope $\% 3$ dsite $\% 26$ authtype $\% 3 d$ crawler\%26jrnl\%3d08740283\%26AN\%3d54284772

29. Fávero $M A B$, Santos $M A$. Infantile autism and familiar stress: a systematic review of the literature. Psychology: Reflection and Criticism.

30. Mugno D, Ruta L, D'Arrigo VG, Mazzone L. Impairment of quality of life in parents of childrem and adolescent with pervasive developmental disorder. Health Qual Life Outcomes. 2007; 5: 22.

31. Garcia EL, Banegas JR, Perez-Regadera AG, Cabrera RH, Rodriguez-Artalejo F. Social network and health related quality of life in older adults: a population based study in Spain. Qual life Res. 2005; 14: 511-20.

32. Greenberg MT, Domitrovich C, Bumbarger B. The prevention of mental disorders in school-aged children: Current State of the field. Prev Treat. 2001; 4(1): 51-9.

33. Nakatani AYK, Souto CCS, Paulette LM, Mel TS, Souza MM. Informal caregivers of olds profile with defict of selfcare attended by Family Health Program. Nursing Eletronic Journal. (online). 2003; 15(3): 170-9.

34. Lemoas ND, Gazzola JM, Ramos LR. Taking care of patient with Alzheimer: the impact of the desease in caregiver. Health and Sociely. 2006; 15(3): 170-9.

35. Silva ST. Quality of life of caregivers of people with hearing disorder. Tesis (Master's Degree). Itajaí: Vale do Itajaí University; 2008.

36. Grelha PASS. Quality of life of dependent olds informal caregivers in home context. Tesis (Master's Degree). (online) Lisbon: University of Lisbon; 2009. Available in: http://repositorio.ul.pt/ bitstream/10451/1090/21226 ulsd057824 td.pdf

Publish in International Archives of Medicine

International Archives of Medicine is an open access journal publishing articles encompassing all aspects of medical science and clinical practice. IAM is considered a megajournal with independent sections on all areas of medicine. IAM is a really international journal with authors and board members from all around the world. The journal is widely indexed and classified Q1 in category Medicine. 